The Journal of Animal \& Plant Sciences, 31(2): 2021, Page: 432-440

ISSN (print): 1018-7081; ISSN (online): 2309-8694

\title{
THE HYDROALCOHOLIC EXTRACT OF ROSMARINUS OFFICINALIS ATTENUATES LIVER DAMAGE AFTER BILE-DUCT LIGATION IN RATS
}

\author{
H. Sadeghi ${ }^{\# 1}$, N. Azarmehr ${ }^{\# 2}$, M. Mansourian ${ }^{1}$, B. Khalvati ${ }^{1}$, E. P. Kokhdan ${ }^{1}$, Z. Salehpour ${ }^{1}$, A. Asfaram ${ }^{1}$ and A. H. \\ Doustimotlagh $^{* 1,3}$ \\ ${ }^{1}$ Medicinal Plants Research Center, Yasuj University of Medical Sciences, Yasuj, Iran \\ ${ }^{2}$ Student Research Committee, Yasuj University of Medical Sciences, Yasuj, Iran \\ ${ }^{3}$ Department of Clinical Biochemistry, Faculty of Medicine, Yasuj University of Medical Sciences, Yasuj, Iran \\ "These authors contributed equally to this work. \\ *Correspondence Author’s e-mail: amirhossein.dousti@yums.ac.ir
}

\begin{abstract}
The aim of the present study was to investigate the possible hepatoprotective effects of hydroalcoholic extract of Rosmarinus officinalis (RO) against liver damage in bile duct ligation (BDL)-induced cholestatic rats. Thirty-four male Wistar rats $(225 \pm 25 \mathrm{~g})$ were randomly divided into four groups; sham control (SC, N=7), BDL (N=9), BDL+ 500 $\mathrm{mg} / \mathrm{kg} /$ day hydroalcoholic extract of $\mathrm{RO}(\mathrm{N}=9)$, and $\mathrm{BDL}+50 \mathrm{mg} / \mathrm{kg} /$ day silimarin $(\mathrm{N}=9)$. Two weeks later, the rats were sacrificed, the blood and liver were collected for liver enzyme, plasma and hepatic oxidative stress markers, antioxidant enzymes activity and hematoxylin and eosin staining. The BDL model significantly elevated the plasma oxidative stress markers and liver enzymes, as well as decreased the liver total thiol and ferric reducing antioxidant power as compared to SC group $(\mathrm{p} \leq 0.05)$. Hydroalcoholic extract of $\mathrm{RO}$ and silimarin significantly reduced liver enzymes and histology indices $(\mathrm{p} \leq 0.05)$, however, they did not show a significant effect on oxidative stress markers. It was concluded that the hydroalcoholic extract of Rosmarinus officinalis has a hepatoprotective effect on liver damage in rats induced by BDL.
\end{abstract}

Keywords: Liver; Cholestasis; Bile duct ligated; Rosmarinus officinalis.

https://doi.org/10.36899/JAPS.2021.2.0232

Published online October 03,2020

\section{INTRODUCTION}

The liver is the main source of metabolism in our body. Thus, its role in maintaining, functioning and homeostasis of the body is significant. Chronic liver disease is a major cause of global health problems, causing around 800,000 deaths worldwide annually (Saleh et al., 2015). Cholestasis is a common liver disease (Alaca et al., 2017). Any condition in which the flow of bile from the liver is slowed or blocked is called cholestasis, which results in abnormal accumulation of bile acids. Extrahepatic cholestasis may be due to bile duct tumors, duct narrowing, stones in the bile ducts such as cholesterol rocks, pancreatitis, and pancreatic tumor (Zhang et al., 2015, Shaker et al., 2015). In contrast, intrahepatic cholestasis can occur due to alcoholic liver disease, liver abscess, tuberculosis, and viral hepatitis. Clinically, cholestasis is associated with symptoms such as fatigue, itching, jaundice, dark urine and pale stools (Shaker et al., 2015). The mechanism of hepatic damage in cholestasis are multifactorial, however, remaining bile acids, oxidative stress and inflammation are important factors contributing to cholestatic damage (Pan et al., 2010). Bile acids increases the oxidative modification of lipids, proteins, and nucleic acids which eventually causes apoptosis or necrosis of the liver cells. In addition, bile acids also affect the kupffer cells to produce reactive oxygen species (ROSs), thereby increasing hepatocellular damage (Gonzalez-Sanchez et al., 2016). Several studies show that ROSs play an important role in the pathogenesis of liver injury and biliary obstruction (Ara et al., 2005, Terzioglu et al., 2017, Montilla et al., 2001, Chen et al., 2009). Oxidative stress has been shown to alter the shape of the hepatic stellate cells into activated star cells that would induce fibrosis (Kabirifar et al., 2017a). It is known that cells are protected by the balance between production and decomposition of ROSs against potential cytotoxicity. ROSs in normal mode play an important role in signaling and homeostasis of the cell, however, excessive production of ROSs effect lipids, proteins, carbohydrates, and nucleic acids. Oxidative stress occurs as a result of an imbalance between the oxidants (such as ROS) and antioxidants (Ihsan et al., 2018). Normal cells have a number of enzymatic and nonenzymatic endogenous defense systems to protect them from oxidants. The enzymatic defense system includes superoxide dismutase (SOD), catalase (CAT), and glutathione peroxidase (GPX). They quickly eliminate ROSs such as superoxide anion, hydrogen peroxide and hydroxyl free radicals (Lee et al., 2004). The best and most common method for measuring free radicals and oxidative stress is to determine the products 
of the reaction of free radicals with biomolecules such as lipids, proteins, and nucleic acids (Salmaninejad et al., 2017).

Medicinal plants have active biological compounds that can be used as alternatives or complement conventional drugs with a wide range of medicinal properties (Wang et al., 2017). Rosmarinus officinalis (RO) is a Mediterranean herb that grows in the North Africa, South-Europe and the United States, but today it is cultivated in different parts of the world due to its aromatic properties (Rašković et al., 2014). This plant is from family of lamiaceae and contains at least $1 \%$ volatile oil. In traditional medicine, this plant is used to treat headaches, migraines, blood pressure, liver problems, and physical and mental fatigue. Also, the use of RO facilitates the bile flow and reduces the liver enzymes; therefore, it is used as a hepatoprotective agent and choleretic in traditional medicine (Tai et al., 2012, Rašković et al., 2014, Al-Sereiti et al., 1999). Moreover, several studies have been reported anti-diabetic (Soliman, 2013), anti-inflammatory (Mengoni et al., 2011), antioxidant (Selmi et al., 2017), renal protective (Azab et al., 2014) and hepatoprotective (Sotelo-Felix et al., 2002, Amin and Hamza, 2005) properties of this plant. According to available reports, the most antioxidant compounds of $\mathrm{RO}$ are carnosicacid and carnosol (Gutiérrez et al., 2010). Bile duct ligation (BDL) is an animal model of chronic liver injury (Chen et al., 2009, Kabirifar et al., 2017a, Heidari et al., 2017) that the morphological changes in this model animal are similar to human cholestasis/cirrhosis (Heidari et al., 2017). Considering the present of antioxidant compounds such as carnosicacid and carnosol in RO plant and the role of oxidants in the pathogenesis of liver cholestasis induced by BDL, in the current study, the hydroalcoholic extract of this plant was used to investigate its potential protective effects against BDL induced liver cholestasis.

\section{MATERIALS AND METHODS}

Preparations of Rosmarinus officinalis hydroalcoholic extract: Plant leaves were collected from forests around Yasuj in Iran, and were then cleaned and dried in the room with direct air for several days. Afterwards, they were crushed and powdered. In the next step, $100 \mathrm{~g}$ of the powder was added to $1000 \mathrm{ml}$ of the solvent $(70 \%$ ethanol). The resulting mixture was placed at $37{ }^{\circ} \mathrm{C}$ for $48 \mathrm{~h}$. The solution was then filtered with Whatman filter paper Grade 1. The resulting mixture was condensed by rotary under a vacuum condition, and the extract was then dried at $50{ }^{\circ} \mathrm{C}$ of an incubator and finally kept at $-20^{\circ} \mathrm{C}$.

Animals and experimental protocols: In the present study, 34 male Wistar rats weighing from $200 \mathrm{~g}$ to $250 \mathrm{~g}$ were used and adapted for 1 week before the experiments. The rats were kept in the animal centers of
Yasuj University of Medical Sciences in a 12-h light/dark cycle while having free access to rat feed diet and drinking water. All experimental procedures were approved by the current ethical considerations of local ethical committee (Grant number code: IR.YUMS.REC.1396.129) and animals were used according to "Principles of Laboratory Animal Care" (NIH Publication No. 86-23). Animals were divided into four groups as follows: sham control ( $\mathrm{SC}, \mathrm{N}=7$ ), BDL alone $(\mathrm{N}=9), \quad \mathrm{BDL}+500 \mathrm{mg} / \mathrm{kg} \quad \mathrm{BW}$ hydroalcoholic extract of RO $(\mathrm{N}=9)$, and $\mathrm{BDL}+50 \mathrm{mg} / \mathrm{kg} \mathrm{BW}$ silimarin. Rats were anesthetized intraperitoneally with ketamine $\mathrm{HCl} 50 \mathrm{mg} / \mathrm{kg}$ and xylazine $\mathrm{HCl} 10 \mathrm{mg} / \mathrm{kg}$ before surgical procedure. In brief, the general bile duct was exposed to sterile condition via a midline abdominal incision. It was then carefully double-ligated with 3-0 silk and sectioned between ligatures. Sham group rats received an identical laparotomy and handling of the common bile duct without any ligation. Treated rats received daily hydroalcoholic extract of RO 500 $\mathrm{mg} / \mathrm{kg} /$ day or silimarin $50 \mathrm{mg} / \mathrm{kg} /$ day orally for 14 days after the surgery. Finally, 14 days after the BDL operation, the blood was collected by puncturing the heart under the deep anesthesia, and the animals were sacrificed. Liver tissue from each rat was removed and divided into two parts as follows: the first part was used for preparing a homogenized tissue, and the second part was fixed with $10 \%$ formalin for histology.

Biochemical examinations: Blood samples were collected in heparin-containing tubes and centrifuged at $3000 \mathrm{rpm}$ for $10 \mathrm{~min}$. Subsequently, the plasma was removed and froze at $-20{ }^{\circ} \mathrm{C}$ for a biochemical analysis. Plasma total protein (TPRO), alkaline phosphatase (ALP), alanine aminotransferase (ALT), and aspartate aminotransferase (AST) as indicators of a liver injury were measured by standard diagnostic kits (Pars Azmoon, Iran).

Oxidative stress markers: Liver tissue was homogenized $(10 \%, w / v)$ using a homogenizer (IKA Werke Ultra-Turrax T25 basic homogenizer, Germany) in PBS (10 mmol L-1, $\mathrm{pH} 7.4)$ after cutting off the liver into small pieces. The homogenate was centrifuged at $10000 \times g$ for $10 \mathrm{~min}$ at $4{ }^{\circ} \mathrm{C}$. The amounts of ferric reducing antioxidant power (FRAP), protein carbonyl (PCO), and total thiol (tSH) content were spectrophotometrically determined in the supernatant of liver tissues.

Determination of PCO content: Homogenate and plasma samples were incubated at the room temperature with 2,4-dinitrophenylhydrazine $\left(10 \mathrm{mmol} \mathrm{L}^{-1}\right)$ in $\mathrm{HCl} 2$ mol L $\mathrm{L}^{-1}$ for $1 \mathrm{~h} .50 \%$ trichloroacetic acid was then added to the microtubes and washed by a 1:1 ethanol/ethyl acetate solution. Afterwards, the guanidinium hydrochloride solution $\left(6 \mathrm{~mol} \mathrm{~L} \mathrm{~L}^{-1}\right)$ was added and 
samples were incubated at $37^{\circ} \mathrm{C}$ for $15 \mathrm{~min}$. Finally, the absorbance of supernatant was read at $370 \mathrm{~nm}$; and the PCO content was calculated using a molar absorption coefficient of $2.2 \times 10^{4} \mathrm{~mol} \mathrm{~L}{ }^{-1} . \mathrm{cm}^{-1}$ (Sadeghi et al., 2019).

Determination of tSH: Determination of tSH group is based on the reaction of the 5,5'-dithiobis-(2-nitrobenzoic acid) or DTNB with thiol groups to obtain the mixed 2nitro-5-thiobenzoic acid (TNB) and disulfide. In brief, tSH groups were measured by adding $25 \mu \mathrm{L}$ of sample, $10 \mu \mathrm{L}$ of DTNB, $150 \mu \mathrm{L}$ of Tris-EDTA, and $790 \mu \mathrm{L}$ of absolute methanol. The test tube was mixed gently using the pipette and kept at the room temperature for $15 \mathrm{~min}$. The absorbance of supernatant was determined at 412 $\mathrm{nm}$, and tSH groups were calculated using a molar absorption of 13,600 mol L-1. $\mathrm{cm}^{-1}$ (Azarmehr et al., 2019).

Determination of nitric oxide (NO) metabolite: Nitrite level was measured in plasma as an index of $\mathrm{NO}$ formation according to the Griess reaction (Sadeghi et al., 2019).

Determination of the FRAP: FRAP was determined according to Benzie and Strain method (Benzie and Strain, 1996). In brief, $33 \mu \mathrm{L}$ of sample was added to $1000 \mu \mathrm{L}$ of FRAP reagent $\left[300 \mathrm{mmol} \mathrm{L}^{-1}\right.$ acetate buffer with the $\mathrm{pH}$ of $3.6,10 \mathrm{mmol} \mathrm{L^{-1 }}$ TPTZ (2,4,6-Tri(2pyridyl)-s-triazine) in $40 \mathrm{mmol} \mathrm{HCL}$, and $20 \mathrm{mmol} \mathrm{L}^{-1}$ $\mathrm{FeCl}_{3} \cdot 6 \mathrm{H}_{2} \mathrm{O}$ in the ratio of $\left.10: 1: 1\right]$ and incubated at $37^{\circ} \mathrm{C}$ for $10 \mathrm{~min}$. The absorbance of the resulting blue color was measured against the reagent blank $(1000 \mu \mathrm{L}$ of FRAP reagent $+33 \mu \mathrm{L}$ of distilled water) at $593 \mathrm{~nm}$.

Determination of Malondialdehyde (MDA): Malondialdehyde was determined in plasma samples as thiobarbituric acid-reactive substances (TBA-RS) according to Ohkawa et al. method (Ohkawa et al., 1979).

Determination of antioxidant enzyme activities: The activities of antioxidant enzymes GPX, SOD, and CAT in a homogenized tissue were measured using ELISA kits
(ZellBio GmbH, Ulm, Germany) based on the kit instructions.

Histological evaluation: Histopathologic evaluation was done by taking a liver tissue and fixing in $10 \%$ formalin buffer. In the next step, the samples were dehydrated using alcohol, and embedded in paraffin. Afterwards, 5 micron sections were prepared and stained with hematoxylin \& eosin staining.

Statistical analysis: The statistical analysis was conducted using SPSS software (V.17). The Kolmogorov- Smirnov test was done for the assessment of normality. The quantitative variables including biochemical and oxidative stress markers were evaluated by one-way ANOVA with Tukey's and LSD post hoc tests. A $P$-value $\leq 0.05$ was considered as the statistical significance.

\section{RESULTS AND DISCUSSION}

Bile duct ligation causes almost similar changes to those in humans; hence, this model was commonly used to induce cholestasis and biliary cirrhosis in animals (Colares et al., 2016). In the present study, BDL model was used to investigate hepatoprotective and antioxidant effects of a hydroalcoholic extract of $\mathrm{RO}$ on liver cholestasis. In BDL rats, liver changes were improved during the first 4 days and increased markedly during 7 to 14 days after the surgery (Ohta et al., 2003).

In the present study, amounts of AST, ALT, and ALP enzymes in the BDL group indicated a significant increase compared to the SC group ( $P$-value $\leq 0.05$, Table 1). The ALP enzyme is present in the hepatocyte plasma membrane, when bile acids accumulate in the liver; it acts as a detergent, thereby releasing enzymes from the plasma membrane of hepatocytes. Bile acids also increase the ALP synthesis. Aminotransferase enzymes such as ALT and AST are found within the hepatocyte cytoplasm; hence, amounts of these enzymes do not increase to the same amount in the liver cholestatic disease.

Table 1. Effect of hydroalcoholic extract of Rosmarinus officinalis on plasma biochemical parameters in BDLinduced rats.

\begin{tabular}{lllll}
\hline Groups & ALT (U/L) & AST (U/L) & ALP (U/L) & TPRO mg/dl \\
\hline SC & $36.40 \pm 6.67$ & $87.96 \pm 10.86$ & $447.0 \pm 55.65$ & $7.46 \pm 0.22$ \\
BDL alone & $87.26 \pm 17.91^{\mathrm{a}}$ & $219.21 \pm 16.98^{\mathrm{a}}$ & $1266.38 \pm 188.20^{\mathrm{a}}$ & $7.64 \pm 0.13$ \\
BDL+ RO & $44.23 \pm 12.40^{\mathrm{b}}$ & $136.31 \pm 24.14^{\mathrm{b}}$ & $751.12 \pm 77.98^{\mathrm{b}}$ & $7.66 \pm 0.22$ \\
BDL + S & $37.33 \pm 10.74^{\mathrm{b}}$ & $167.56 \pm 23.10$ & $675.15 \pm 158.76^{\mathrm{b}}$ & $6.59 \pm 0.15$ \\
\hline
\end{tabular}

ALT: alanine aminotransferase; AST: aspartate aminotransferase; ALP: alkaline phosphatase; TPRO: total protein. Each value represents the mean \pm SEM. SC: sham control; BDL: Bile duct ligation; RO: $500 \mathrm{mg}$ hydroalcoholic extract of Rosmarinus officinalis; S: $50 \mathrm{mg}$ silimarin. aSignificantly different from that of the SC group $(\mathrm{p} \leq 0.05)$. ' Significantly different from that of the BDL alone group $(\mathrm{p} \leq 0.05)$. 
In the histopathological evaluation, the SC group showed normal cellular structures with obvious liver cells, while nuclei were clearly observed. In the BDL group, tissue fibrosis, severe biliary duct hyperplasia and inflammatory infiltration of white blood cells were observed in comparison with the $\mathrm{SC}$ group. In the BDL group receiving the hydroalcoholic extract of RO, moderate bile duct hyperplasia was seen, but no tissue fibrosis was observed (Figure 1). The liver histology analysis confirmed biochemical results and indicated that the cholestasis occurred after 14 days of BDL.
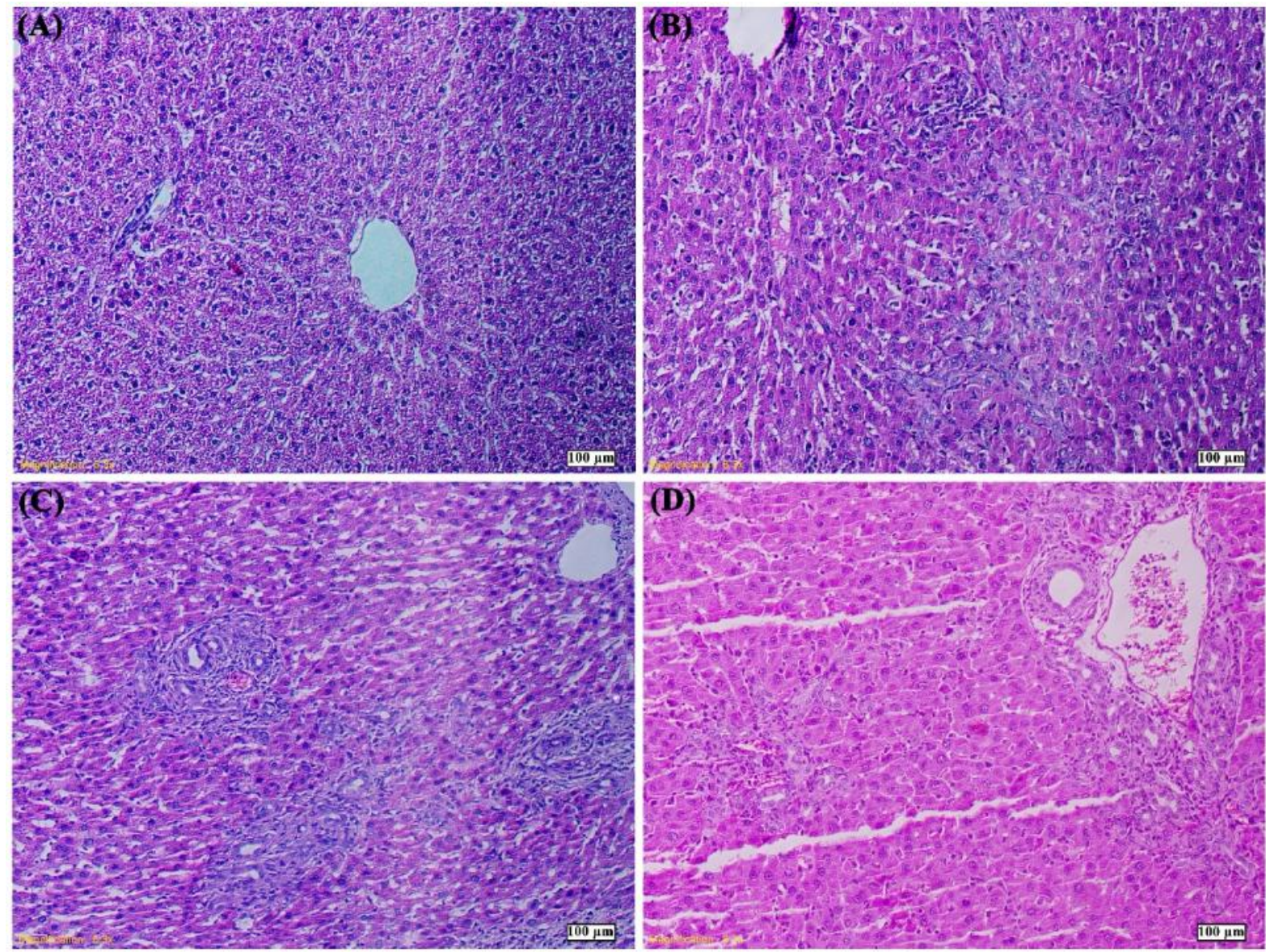

Figure 1. Photomicrograph of rat liver stained with hematoxylin and eosin $(10 \times)$. (A) Sham control rat. (B) Bile duct ligated rat. (C) BDL rat treated with $500 \mathrm{mg} / \mathrm{kg}$ hydroalcoholic extract of Rosmarinus officinalis. (D) BDL rat treated with $50 \mathrm{mg} / \mathrm{kg}$ silimarin.

Rašković et al. (2014) indicated that the RO oil at two doses of 5 and $10 \mathrm{mg} /$ day significantly decreased the levels of ALT and AST in carbon tetrachloride induced liver injury (Rašković et al., 2014). Furthermore, a study by Galisteo et al. (2000) on the hepatic damage induced by thioacetamide and a research by Lucarini et al. (2014) on acetaminophen induced liver injury indicated that RO ethanolic and hydroalcoholic extracts significantly decreased ALT, AST, and ALP activities (Galisteo et al., 2000, Lucarini et al., 2014). In agreement with these studies, our finding showed that in the BDL group receiving $500 \mathrm{mg} / \mathrm{kg} \mathrm{RO}$, the values of AST, ALT, and ALP activities enzymes were significantly lower than those of BDL group $(P$-value $\leq 0.05$, Table 1$)$.
It should be noted that the AST and ALT enzymes are predominantly present in cells and an increase in plasma is due to the damage to hepatocytes, resulting in the release of these enzymes into the extracellular space. In the present study, amounts of these enzymes in the BDL group receiving RO extract were markedly lower than the BDL group, which RO extract probably prevents the activation of kupffer cells by reducing the inflammatory and fibrogenic intermediates, thereby significantly inhibits the release of these enzymes (Selmi et al., 2017).

Due to the imbalance between pro-oxidants and antioxidant system in cells, the oxidative stress occurs and causes damage to biomolecules such as lipids and proteins. Our findings showed that the level of liver tSH 
and FRAP significantly decreased in the BDL group compared with the SC group, while liver PCO content did not show significant changes (Table 2). In addition, the levels of plasma FRAP, tSH, PCO and NO metabolite significantly increased in the BDL group compared with the $\mathrm{SC}$ group ( $\mathrm{P} \leq 0.05$, Table 3$)$. However, the treatment of hydroalcoholic extract of RO at dose of $500 \mathrm{mg} / \mathrm{kg}$ and silimarin at dose of $50 \mathrm{mg} / \mathrm{kg}$ had no significant effect on these parameters.

Table 2. Effect of hydroalcoholic extract of Rosmarinus officinalis on liver oxidative stress markers in BDLinduced rats.

\begin{tabular}{lccc}
\hline Groups & tSH $(\boldsymbol{\mu m o l} / \mathbf{g}$ tissue $)$ & PCO $(\boldsymbol{\mu m o l} / \mathbf{g}$ tissue $)$ & FRAP $(\boldsymbol{\mu m o l} / \mathbf{g}$ tissue $)$ \\
\hline SC & $7.64 \pm 0.57$ & $2.87 \pm 0.07$ & $1490.00 \pm 54.64$ \\
BDL alone & $4.22 \pm 0.66^{\mathrm{a}}$ & $2.81 \pm 0.03$ & $1103.16 \pm 91.51^{\mathrm{a}}$ \\
BDL+ RO & $4.60 \pm 0.54^{\mathrm{a}}$ & $2.87 \pm 0.08$ & $1116.50 \pm 51.53^{\mathrm{a}}$ \\
BDL + S & $2.97 \pm 0.38^{\mathrm{a}}$ & $2.74 \pm 0.05$ & $1055.87 \pm 84.34^{\mathrm{a}}$ \\
\hline
\end{tabular}

tSH: total thiol group; PCO: protein carbonyl; FRAP: ferric reducing antioxidant power. Each value represents the mean \pm SEM. SC: sham control; BDL: Bile duct ligation; RO: $500 \mathrm{mg}$ hydroalcoholic extract of Rosmarinus officinalis; S: $50 \mathrm{mg}$ silimarin.

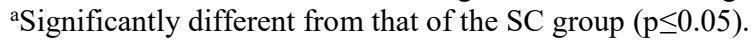

Table 3. Effect of hydroalcoholic extract of Rosmarinus officinalis on plasma oxidative stress markers in BDL-induced rats.

\begin{tabular}{|c|c|c|c|c|c|}
\hline Groups & FRAP $(\mu \mathrm{mol} / \mathrm{L})$ & PCO $(\mu \mathrm{mol} / \mathrm{L})$ & MDA (nmol/L) & $\begin{array}{l}\text { NO metabolite } \\
(\mu \mathrm{mol} / \mathrm{L})\end{array}$ & tSH $(\mu \mathrm{mol} / \mathrm{L})$ \\
\hline $\mathrm{SC}$ & $879.00 \pm 50.94$ & $3.77 \pm 0.13$ & $70.51 \pm 21.37$ & $9.08 \pm 1.25$ & $4.06 \pm 0.67$ \\
\hline BDL alone & $1451.08 \pm 128.59^{\mathrm{a}}$ & $4.49 \pm 0.06^{\mathrm{a}}$ & $97.48 \pm 18.34$ & $17.37 \pm 1.20^{\mathrm{a}}$ & $7.25 \pm 0.96^{\mathrm{a}}$ \\
\hline $\mathrm{BDL}+\mathrm{RO}$ & $1502.33 \pm 69.52^{\mathrm{a}}$ & $4.53 \pm 0.10^{\mathrm{a}}$ & $119.12 \pm 15.08$ & $19.68 \pm 1.39^{\mathrm{a}}$ & $7.63 \pm 0.66^{\mathrm{a}}$ \\
\hline $\mathrm{BDL}+\mathrm{S}$ & $1541.50 \pm 100.54^{\mathrm{a}}$ & $4.43 \pm 0.21^{\mathrm{a}}$ & $129.80 \pm 4.42$ & $19.26 \pm 2.04^{\mathrm{a}}$ & $7.14 \pm 0.59$ \\
\hline
\end{tabular}

FRAP: ferric reducing antioxidant power; PCO: protein carbonyl; MDA: malondialdehyde; NO metabolite: nitric oxide metabolite; $\mathrm{tSH}$ : total thiol group. Each value represents the mean \pm SEM. SC: sham control; BDL: Bile duct ligation; RO: 500 mg hydroalcoholic extract of Rosmarinus officinalis; S: $50 \mathrm{mg}$ silimarin. ${ }^{a}$ Significantly different from that of the SC group $(\mathrm{p} \leq 0.05)$.

MDA is a tissue injury index produced in BDLinduced rats due to the toxicity caused by ROS (Catalá, 2012). In a study by Alaca et al. (2017), MDA levels in the BDL group were higher than the control group (Alaca et al., 2017). Zhao et al. (2017) found that the levels of MDA augmented after surgery in BDL rats (Zhao et al., 2018). Abu Taher et al. (2016) studied liver injury induced by carbon tetrachloride (Abu Taher et al., 2016), and Selmi et al. (2016) studied alloxan-induced diabetes (Selmi et al., 2017). They found that the RO extract significantly decreased MDA. In the present study, MDA slightly increased in the plasma of rats in the BDL group; however, the infusion of RO extract into BDL rats did not have any significant effect on plasma MDA levels.

Protein carbonyl has been used as a marker for reactive oxygen-mediated alterations in proteins (Bayr, 2005). In a study by Terzioglu et al. (2016), the mean level of PCO in the BDL group was significantly higher than the control group (Terzioglu et al., 2017). In consistent with these studies, the results of the present study indicated that the PCO level in the BDL group significantly increased compared with the SC group, while the administration of RO hydroalcoholic extract $(500 \mathrm{mg} / \mathrm{kg})$ did not show any significant effect on this factor.
Total thiol (tSH) is a sensitive indicator of oxidative stress that plays a vital role in the defense system against the ROS (Terzioglu et al., 2017). In consistent with the present study, Kabirifar et al. (2017) found that the tSH level of liver tissue in BDL rats significantly decreased compared with SC group (Kabirifar et al., 2017b). Selmi et al. (2017) studied alloxan-induced diabetes and found that the RO extract significantly increased $\mathrm{tSH}$ in the liver tissue (Selmi et al., 2017). Our findings revealed that hepatic tSH levels were significantly higher in BDL rats as compared with the SC group, while the treatment of $\mathrm{RO}$ had no significant effect on it.

Nitric oxide, a molecule with a half-life of only few seconds, is a highly reactive mediator produced in the liver by varied cells such as endothelial, macrophage, hepatocyte, and Kupffer. Studies indicated that this compound was a primary mediator of liver damage (Aksu et al., 2010). Ebrahimkhani et al. (2005) indicated a significant increase in NO (nitrite and nitrate) metabolites in BDL-induced cholestasis rats compared with the control group (Ebrahimkhani et al., 2005). The present study indicated that the amount of NO metabolite in the BDL group was significantly higher than that of SC group, and it was consistent with the previous study 
(Doustimotlagh et al., 2018). However, the RO extract did not effect on this index. In contrary with the results of the present study, Gutiérrez et al. (2009); (Gutiérrez et al., 2010) and Abu Taher et al. (2016) indicated that the RO extract significantly decreased NO levels in carbon tetrachloride-induced rats (Abu Taher et al., 2016). This difference may be due to the different applied animal models, the research duration, and the type of applied extract.

For a comprehensive overview of what occurs in plasma, the total antioxidant status was measured using a FRAP test. In addition, the FRAP level in the liver tissue in the BDL group was significantly lower than the SC group that may be due to the higher production of oxidative agents in the liver tissue. However, the BDL group receiving RO extract did not show any significant changes in FRAP levels in the liver and plasma compared with the alone BDL group.
CAT is a homo-tetramer enzyme that converts hydrogen peroxide into water and oxygen. The SOD enzyme is another key antioxidant defense enzyme that accelerates the conversion of radical anion superoxide to hydrogen peroxide and molecular oxygen (Brioukhanov et al., 2006). GPX is an intracellular antioxidant enzyme that catalyzes hydrogen peroxide to $\mathrm{H}_{2} \mathrm{O}$ for removing its harmful effects (Prasad et al., 2015). Our findings showed that CAT activity significantly increased in the $\mathrm{BDL}$ group compared with the $\mathrm{SC}$ group $(\mathrm{P} \leq 0.05)$; however, the administration of the hydroalcoholic extract of RO to the BDL group had no significant effect on this enzyme (Table 4). GPX activity in the BDL group insignificantly reduced compared with the SC group. Nonetheless, SOD activity in the BDL group did not significant change compared with the other groups.

Table 4. Effect of hydroalcoholic extract of Rosmarinus officinalis on the antioxidant enzymes activity of GPX, SOD and CAT in BDL-induced rats.

\begin{tabular}{lccc}
\hline Groups & CAT $(\mathbf{U} / \mathbf{m l})$ & GPX $(\mathbf{U} / \mathbf{m l})$ & SOD $(\mathbf{U} / \mathbf{m l})$ \\
\hline SC & $25.80 \pm 0.84$ & $439.45 \pm 55.89$ & $31.40 \pm 11.15$ \\
BDL alone & $29.54 \pm 0.51^{\mathrm{a}}$ & $152.34 \pm 71.60$ & $28.80 \pm 0.42$ \\
BDL+ RO & $29.41 \pm 0.54^{\mathrm{a}}$ & $278.32 \pm 91.70$ & $28.86 \pm 3.60$ \\
BDL + S & $28.12 \pm 0.40$ & $439.45 \pm 131.24$ & $26.94 \pm 7.50$ \\
\hline
\end{tabular}

CAT: Catalase; GPX: Glutathione Peroxidase; SOD: Superoxide Dismutase. Each value represents the mean \pm SEM. SC: sham control; BDL: Bile duct ligation; RO: $500 \mathrm{mg}$ hydroalcoholic extract of Rosmarinus officinalis; S: $50 \mathrm{mg}$ silimarin. aSignificantly different from that of the SC group $(\mathrm{p} \leq 0.05)$.

Previous studies indicated that the activities of CAT, SOD, and GPX enzymes decreased in 7, 10, and 45 days after the creation of BDL (Orellana et al., 2000, Ale-Ebrahim et al., 2015, Mansourian et al., 2018). Kim et al. (2013) and Parola et al. (2001) reported that CAT and SOD activities rapidly increased following the BDL operation (Kim et al., 2013, Parola and Robino, 2001). In accordance with Kim et al.' study, the present study indicated that the CAT activity in the BDL group significantly increased compared with the SC group, while the GPX activity insignificantly decreased. Compared with the alone BDL group, GPX activity increased slightly in the RO recipient's BDL group. In consistent with results of the present study, Ozcelik et al. (2014) found that the RO ethanolic extract did not have any effect on the SOD activity (Ozcelik et al., 2014).

Studies have been conducted on the effects of RO on various liver injury models. Previous studies found that the RO methanol extract protected against the acute liver injury caused by carbon tetrachloride (SoteloFelix et al., 2002), and the aqueous RO extract inhibited the acute liver damage induced by azathioprine (Amin and Hamza, 2005). Furthermore, the RO methanol extract could inhibit carbon tetrachloride-induced liver cirrhosis in experimental models (Gutiérrez et al., 2010). Despite various studies on the effects of RO protection on liver damage, there is no study on the impact of this plant extract on BDL-induced liver cholestasis.

Conclusion: In summary, results of the present study indicated that the hydroalcoholic extract of RO plant through its effect on conventional biochemical tests such as ALT, AST and ALP, as well as the improvement of histological parameters reduced BDL-induced liver damage in rats. Despite a significant increase in the levels of oxidative stress markers in the BDL group, the hydroalcoholic extract of RO at a dose of $500 \mathrm{mg} / \mathrm{kg} / \mathrm{BW}$ had no significant effect on these parameters.

Conflict of interest: No conflict of interest

\section{REFERENCES}

Abu Taher, S., H.M. Reza, N. Tabassum, B. Sikder, A. Ulla, N. Subhan, H. Hossain, and A. Alam. (2016). Supplementation of rosemary leaves (Rosmarinus officinalis) powder attenuates oxidative stress, inflammation and fibrosis in carbon tetrachloride $\left(\mathrm{CCl}_{4}\right)$ treated rats. Curr. Nutr. Food. Sci. 12 (4):288-295. 
Aksu, B., H. Umit, M. Kanter, A. Guzel, C. Aktas, S. Civelek, and H. Uzun. (2010). Effects of methylene blue in reducing cholestatic oxidative stress and hepatic damage after bile-duct ligation in rats. Acta. histochem. 112 (3):259-269.

Al-Sereiti, MR., K.M. Abu-Amer, and P. Sena. (1999). Pharmacology of rosemary (Rosmarinus officinalis Linn.) and its therapeutic potentials. Indian. J. Exp. Biol. 37 (2) :124-130.

Alaca, N., D. Özbeyli, S. Uslu, H.H. Şahin, G. Yiğittürk, H. Kurtel, G. Öktem, and B.Ç. Yeğen. (2017). Treatment with milk thistle extract (Silybum marianum), ursodeoxycholic acid, or their combination attenuates cholestatic liver injury in rats: Role of the hepatic stem cells. Turk. J. Gastroenterol. 28:476-484.

Ale-Ebrahim, M., A. Eidi, P. Mortazavi, S.M. Tavangar, and D.M. Tehrani. (2015). Hepatoprotective and antifibrotic effects of sodium molybdate in a rat model of bile duct ligation. J. Trace. Elem. Med. Bio. 29:242-248.

Amin , A., and A.A. Hamza. (2005). Hepatoprotective effects of Hibiscus, Rosmarinus and Salvia on azathioprine-induced toxicity in rats. Life. Sci. 77 (3):266-278.

Ara, C., H. Kirimlioglu, A.B. Karabulut, S. Coban, S. Ay, M. Harputluoglu, V. Kirimlioglu, and S. Yilmaz. (2005). Protective effect of resveratrol against oxidative stress in cholestasis. J. Surg. Res. 127 (2):112-117.

Azab, A.E., F.A. Fetouh, and M.O. Albasha. (2014). Nephro-protective effects of curcumin, rosemary and propolis against gentamicin induced toxicity in guinea pigs: Morphological and biochemical study. AJCEM. 2 (2):28-35.

Azarmehr, N., P. Afshar, M. Moradi, H. Sadeghi, H. Sadeghi, B. Alipoor, B. Khalvati, Z. Barmoudeh, K. Abbaszadeh-Goudarzi, and A.H. Doustimotlagh. (2019). Hepatoprotective and antioxidant activity of watercress extract on acetaminophen-induced hepatotoxicity in rats. Heliyon. 5 (7): e02072.

Bayr, H. (2005). Reactive oxygen species. Crit. Care. Med. 33 (12):S498-S501.

Benzie, I.FF., and J.J. Strain. (1996). The ferric reducing ability of plasma (FRAP) as a measure of "antioxidant power": the FRAP assay. Anal. Biochem. 239 (1):70-76.

Brioukhanov, A.L., A.I. Netrusov, and R.I. Eggen. (2006). The catalase and superoxide dismutase genes are transcriptionally up-regulated upon oxidative stress in the strictly anaerobic archaeon Methanosarcina barkeri. Microbiology. 152 (6): 1671-1677.

Catalá, A. (2012). Lipid peroxidation modifies the picture of membranes from the "Fluid Mosaic Model" to the "Lipid Whisker Model". Biochimie. 94 (1):101-109.

Chen, W.Y., C.J. Chen, J.W. Liao, and F.Ch.Mao. (2009). Chromium attenuates hepatic damage in a rat model of chronic cholestasis. Life. Sci. 84 (17-18):606-614.

Colares, J.R., E.G. Schemitt, R.M. Hartmann, F. Licks, M.d.C. Soares, A.D. Bosco, and N.P. Marroni. (2016). Antioxidant and anti-inflammatory action of melatonin in an experimental model of secondary biliary cirrhosis induced by bile duct ligation. World. J. Gastroenterol. 2 (40):8918.

Doustimotlagh, A.H., A.R. Dehpour, S.E. Moghadam, M. Alaeddini, S. Ostadhadi, and A. Golestani. (2018). A study on OPG/RANK/RANKL axis in osteoporotic bile duct-ligated rats and the involvement of nitrergic and opioidergic systems. Res. Pharm. Sci. 13 (3):239.

Ebrahimkhani, M.R., H. Sadeghipour, M. Dehghani, S. Kiani, S. Payabvash, K. Riazi, H. Honar, P. Pasalar, N. Mirazi, and M. Amanlou. (2005). Homocysteine alterations in experimental cholestasis and its subsequent cirrhosis. Life. Sci. 76 (21):2497-2512.

Galisteo, M., A. Suárez, M.P. Montilla, M.P. Utrilla, J. Jiménez, A. Gil, M.J. Faus, and M.C. Navarro. (2000). Antihepatotoxic activity of Rosmarinus tomentosus in a model of acute hepatic damage induced by thioacetamide. Phytother. Res. 14 (7):522-526.

Gonzalez-Sanchez, E., M.J. Perez, N.S. Nytofte, O. Briz, M. J. Monte, E. Lozano, M. A. Serrano, and J.J. Marin. (2016). Protective role of biliverdin against bile acid-induced oxidative stress in liver cells. Free. Radical. Bio. Med. 97:466-477.

Gutiérrez, R., J.L. Alvarado, M. Presno, O.P. Veyna, C.J. Serrano, and P. Yahuaca. (2010). Oxidative stress modulation by Rosmarinus officinalis in CCl4-induced liver cirrhosis. Phytother. Res. 24 (4):595-601.

Heidari, R., L. Moezi, B. Asadi, M.M. Ommati, and N. Azarpira. (2017). Hepatoprotective effect of boldine in a bile duct ligated rat model of cholestasis/cirrhosis. Pharmanutrition. 5 (3): 109 -117 .

Ihsan, A.U., F.U. Khan, P. Khongorzul, Kh.A. Ahmad, M. Naveed, S. Yasmeen, Y. Cao, A.Taleb, R. Maiti, and F. Akhter. (2018). Role of oxidative stress in pathology of chronic prostatitis/chronic pelvic pain syndrome and male infertility and 
antioxidants function in ameliorating oxidative stress. Biomed. Pharmacother. 106:714-723.

Kabirifar, R., F. Safari, A. Karimollah, A. Moradi, and E.E. Nasab. (2017a). Hepatoprotective effects of curcumin in rats after bile duct ligation via downregulation of Rac1 and NOX1. J. Nutr. 36:72-78.

Kabirifar, R., F. Safari, A. Karimollah, A. Moradi, and E.E. Nasab. (2017b). Quercetin protects liver injury induced by bile duct ligation via attenuation of Racl and NADPH oxidase1 expression in rats. Hepatob. Pancreat. Dis. 16 (1):88-95.

Kim, H.G., J.M. Han, H.W. Lee, J.S. Lee, S.W. Son, M.K. Choi, D.S. Lee, J.H. Wang, and C.G. Son. (2013). CGX, a multiple herbal drug, improves cholestatic liver fibrosis in a bile duct ligationinduced rat model. J. Ethnopharmacol. 145 (2):653-662.

Lee, J.Y., S.H. Lee, H. J. Kim, J.M. Ha, S.H. Lee, J.H. Lee, and B. J. Ha. (2004). The preventive inhibition of chondroitin sulfate against the $\mathrm{CCI}_{4}$-lnduced oxidative stress of subcellular level. Arch. Pharm. Res. 27 (3):340.

Lucarini, R., W.A. Bernardes, M.G. Tozatti, A.A.S. Filho, M.L.A. Silva, C. Momo, A. Eduardo M. Crotti, C.H.G. Martins, and W.R. Cunha. (2014). Hepatoprotective effect of Rosmarinus officinalis and rosmarinic acid on acetaminophen-induced liver damage. Emir. J. Food. Agric. 26 (10):878-885.

Mansourian, M., H. Sadeghi, and A.H. Doustimotlagh. (2018). Activation of the Glutathione Peroxidase by Metformin in the Bile-duct Ligation-induced Liver Injury: In vivo Combined with Molecular Docking Studies. Curr. Pharm. Des. 24 (27):3256-3263.

Mengoni, E.S., G. Vichera, L.A. Rigano, M. L. Rodriguez-Puebla, S.R. Galliano, E.E. Cafferata, O.H. Pivetta, S. Moreno, and A.A. Vojnov. (2011). Suppression of COX-2, IL-1 $\beta$ and TNF$\alpha$ expression and leukocyte infiltration in inflamed skin by bioactive compounds from Rosmarinus officinalis L. Fitoterapia. 82 (3):414-421.

Montilla, P., A. Cruz, F.J. Padillo, I. Tunez, F. Gascon, M.C. Munoz, M. Gomez, and C. Pera. (2001). Melatonin versus vitamin $\mathrm{E}$ as protective treatment against oxidative stress after extrahepatic bile duct ligation in rats. J. Pineal. Res. 31 (2):138-144.

Ohkawa, H., N. Ohishi, and K. Yagi. (1979). Assay for lipid peroxides in animal tissues by thiobarbituric acid reaction. Anal. Biochem. 95 (2):351-358.

Ohta, Y., M. Kongo, and T. Kishikawa. (2003). Melatonin exerts a therapeutic effect on cholestatic liver injury in rats with bile duct ligation. J. Pineal. Res. 34 (2):119-126.

Orellana, M., R. Rodrigo, L. Thielemann, and V. Guajardo. (2000). Bile duct ligation and oxidative stress in the rat: effects in liver and kidney. Comp. Biochem. Physiol C. Toxicol. Pharmacol. 126 (2):105-111.

Ozcelik, M., U.G. Simsek, S. Ceribasi, and M. Ciftci. (2014). Effects of different doses of rosemary oil (Rosmarinus officinalis L.) on oxidative stress and apoptosis of liver of heat stressed quails. Poult. Sci. 78:2014-32.

Pan, P.H., S.Y. Lin, Y.C. Ou, W.Y. Chen, Y.H. Chuang, Y.J. Yen, S.L. Liao, S.L. Raung, and C.J. Chen. (2010). Stearic acid attenuates cholestasisinduced liver injury. Biochem. Biophys. Res. Commun. 391 (3):1537-1542.

Parola, M., and G.Robino. (2001). Oxidative stressrelated molecules and liver fibrosis. J. Hepatol. 35 (2):297-306.

Prasad, P.R., H.B. Singh, and R.J. Butcher. (2015). Synthesis, structure and antioxidant activity of cyclohexene-fused selenuranes and related derivatives. Molecules. 20 (7):12670-12685.

Rašković, A., I. Milanović, N. Pavlović, T. Ćebović, S. Vukmirović, and M. Mikov. (2014). Antioxidant activity of rosemary (Rosmarinus officinalis $L$.) essential oil and its hepatoprotective potential. Complem. Altern. Med. 14 (1):225.

Sadeghi, H., N. Azarmehr, F. Razmkhah, H. Sadeghi, N. Danaei, N. Omidifar, H. Vakilpour, H. Pourghadamyari, A.H. Doustimotlagh. (2019). The hydroalcoholic extract of watercress attenuates protein oxidation, oxidative stress, and liver damage after bile duct ligation in rats. J. Cell. Biochem. 120 (9): 14875-14884.

Saleh, H., A.M. Soliman, A.S. Mohamed, and M.S. Marie. (2015). Antioxidant effect of sepia ink extract on Extrahepatic Cholestasis induced by bile duct ligation in rats. Biomed .Environ. Sci. 28 (8):582-594.

Salmaninejad, A., P. Kangari, and A. Shakoori. (2017). Oxidative stress: development and progression of breast cancer. Tehran. Univ. Med. J. 75 (1):19.

Selmi, S., K. Rtibi, D. Grami, H. Sebai, and L. Marzouki. (2017). Rosemary (Rosmarinus officinalis) essential oil components exhibit antihyperglycemic, anti-hyperlipidemic and 
antioxidant effects in experimental diabetes. Pathophysiology. 24 (4):297-303.

Shaker, S.M., H.K. Kamel, and S.MF. Ezzat. (2015). The role of rosuvastatin in experimentally induced hepatic cholestasis in adult male albino rats: a histological and immunohistochemical study. Egypt. J. Histol. 38 (2):219-227.

Soliman, G. ZA. (2013). Effect of Rosmarinus officinalis on lipid profile of streptozotocin-induced diabetic rats. Egypt. J. Hosp. Med 53:809-815.

Sotelo-Felix, JI., D. Martinez-Fong, P. Muriel, R.L. Santillan, D. Castillo, and P. Yahuaca. (2002). Evaluation of the effectiveness of Rosmarinus officinalis (Lamiaceae) in the alleviation of carbon tetrachloride-induced acute hepatotoxicity in the rat. J. Ethnopharmacol. 81 (2):145-154.

Tai, J., S. Cheung, M. Wu, and D. Hasman. (2012). Antiproliferation effect of Rosemary (Rosmarinus officinalis) on human ovarian cancer cells in vitro. Phytomedicine. 19 (5):436443 .
Terzioglu, D., L. Uslu, G. Simsek, P. Atukeren, H. Erman, R. Gelisgen, S. Ayvaz, B. Aksu, and H. Uzun. (2017). The effects of hyperbaric oxygen treatment on total antioxidant capacity and prolidase activity after bile duct ligation in rats. J. Invest. Surg. 30 (6):376-382.

Wang, Y.Y., S.Y. Lin, W.Y. Chen, S.L. Liao, C.C. Wu, P.H. Pan, S.T. Chou, and C.J. Chen.(2017). Glechoma hederacea extracts attenuate cholestatic liver injury in a bile duct-ligated rat model. J. Ethnopharmacol. 204:58-66.

Zhang, L., Y. Cheng, X. Du, S. Chen, X. Feng, Y. Gao, S. Li, L. Liu, M. Yang, and L. Chen. (2015). Swertianlarin, an herbal agent derived from Swertia mussotii Franch, attenuates liver injury, inflammation, and cholestasis in common bile duct-ligated rats. Evid. Based. Complement. Alternat. Med. 2015: 1-11.

Zhao, S., N. Li, W. Zhao, H. Liu, M. Ge, Y. Zhang, L. Zhao, X. You, H. He, and R. Shao. (2018). Dchiro-inositol effectively attenuates cholestasis in bile duct ligated rats by improving bile acid secretion and attenuating oxidative stress. Acta. Pharm. Sin. 39 (2): 213-221. 